\title{
Sobras e sombras nobres e plebeias do século XVI
}

\author{
Manoel Mourivaldo Santiago-Almeida* \\ Manoella Neres Jubilato* \\ Cátia Schreiner ${ }^{* *+}$
}

RESUMO: Tendo como base o livro Ditos portugues dignos de memória (1997) - elaborado a partir da tradição oral do português quinhentista (registros de fala extraídos do cotidiano da nobreza à plebe) - este texto destaca lexias e expressões consideradas fora de uso no atual português europeu, e que, em contrapartida, são do uso corrente no português brasileiro de hoje.

Palavras-chave: Português europeu; português brasileiro; dialeto caipira; léxico.

ABSTRACT: Based on the book Ditos portugues dignos de memória (1997) - which deals with the oral tradition of the portuguese language of the 1500s ( with register of speech taken from daily language from nobility to the common man ) - this text highlights lexicon and expressions currently considered to be out of use in European Portuguese, but which are common in present-day Brazilian Portuguese.

Keywords: European Portuguese; Brazilian Portuguese; countryside dialect; lexicon.

\begin{abstract}
"Uma cousa pequena ou uma palavra faz conhecer melhor os costumes das pessoas que as disseram que os infinitos inimigos mortos em batalhas e as cidades destruídas e reinos conquistados." (Autor desconhecido: Ditos portugueses, 1997: 5).
\end{abstract}

\footnotetext{
* Universidade de São Paulo. E-mail: msantiago@usp.br

** Universidade de São Paulo.E-mail: manoella.jubilato@usp.br

*** Universidade de São Paulo.E-mail: catia.schreiner@usp.br
} 


\section{Manoel Mourivaldo Santiago-Almeida; Manoella Neres Jubilato; Cátia Schreiner}

\section{Introdução}

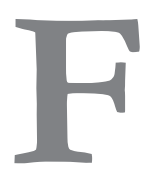

oi publicado neste periódico (1998: 233-239) a resenha do livro, de autor desconhecido, Ditos portugueses dignos de memória (História íntima do século XVI anotada e comentada por José Hermano Saraiva). Mem Martins: Publicações Europa-América, $1997 .{ }^{1}$ Naquele momento - além de destacar o principal objetivo do livro que, por ser um registro oral, revelador da intimidade e do cotidiano quinhentista da realeza portuguesa e sua gente, é o de destacar aspectos intimistas da história social e política de Portugal ${ }^{2}$ - valemo-nos da história sem censura, onde ninguém é esquecido, dos monarcas ao menor sujeito do reino, contada numa linguagem livre, extraída da tradição oral, e, por isso mesmo, mais popular e usual, com a finalidade de chamar a atenção para o código linguístico ou para $\mathrm{a}(\mathrm{s})$ variedade(s) corrente(s) no século da primeira migração portuguesa para o Brasil. O interesse fixou-se, naquela resenha, no nível semântico.

Para tanto, foram apontadas algumas lexias e expressões e/ou construções idiomáticas, que, por serem consideradas arcaicas e fora de uso no atual português europeu, mereceram, por parte do editor, notas elucidativas. Nas notas são dados os equivalentes modernos desses termos e construções, e também há informações sobre personagens e acontecimentos referidos no texto, além de explicações dos motes mais absurdos. Por explicar ao leitor aquilo que era considerado piada no século XVI, o editor se considera um atrevido e justifica sua atitude valendo-se do tempo já decorrido de tais anedotas, que, sem observações a respeito do seu contexto discursivo, poderiam perder a graça, prejudicando um dos objetivos da publicação.

De acordo com o texto introdutório (p. 11), o original dos Ditos portugueses está perdido, mas dele chegaram até os dias atuais cópias relativamente numerosas. Infere-se daí que a obra despertou interesse em sua época (século XVI) e ainda nos séculos XVII e XVIII. Das cópias examinadas por J. H. Saraiva, as mais completas são a da Seção de Reservados da Biblioteca Nacional, cota ms. 666, escrita nos princípios do século XVII, e a da Biblioteca da Academia das Ciências de Lisboa, cota ms. 120 azul, escrita em meados do século XVIII. O texto publicado é o do ms. 666 da Biblioteca Nacional, com uma ou outra correção, sempre assinalada em nota, resultante do manuscrito da Academia.

2 Ditos portugueses, conforme texto da contra-capa, pode ser assim descrito: "Cruel depoimento da sociedade do século XVI, esta compilação de ditos alheios retrata com mordacidade a sociedade em que o autor [desconhecido] viveu, revelando os aspectos mais secretos e, por vezes, escandalosos das vivências cotidianas. Vem à superfície o Portugual íntimo e profundo, das situações comezinhas, das mesquinharias, da inveja, num tom irreverente que causa uma velada preocupação com a situação que se vivia. Numa linguagem debragada e eivada de sarcasmo, denuncia-se um país fendido pela intolerância e pela cupidez, onde se assiste ao naufragar das estruturas morais e ao esborar das estruturas económicas". 
O que chama a atenção nisso tudo, considerando a discussão, que não é nova, sobre o português brasileiro $(\mathrm{PB})$ tender mais à manuteção, versus à tendência de inovação do português europeu (PE), é observar que muitas dessas palavras e construções idiomáticas, consideradas hoje, em Portugal, arcaicas e caídas em deuso, são correntes no Brasil. Isso revela que o PB, principalmente o do meio rural, sem descartar por completo o do meio urbano, conserva traços de um português antigo. ${ }^{3}$ Entendendo aqui por antigo, o português do período arcaico ao século XIX.

Agora, com mais dados disponíveis para um novo cotejo, o interesse continua fixado no mesmo nível semântico-lexical. ${ }^{4}$ Daí, podemos medir mais um pouco a distância e/ou proximidade entre o que se diz ser o PE e o PB, tendo na lente da lupa, material escrito, e no diafragma do estetoscópio, material oral da variedade popular, incluindo aí o dialeto caipira e as variedades que resultaram dele nas áreas de sua expansão, foco de nosso estudo. ${ }^{5}$

\section{Ditos: expressões}

Comecemos pelo dito 368 (p. 143), atribuído ao primeiro governador do Brasil colonial, Tomé de Sousa, primeiro governador-geral do Brasil (15491553) e vedor de el-rei Dom João, o terceiro, quando, em visita a Dom Luís Fernandes de Meneses, filho do arcebispo de Lisboa, que havia arribado do Brasil, ouviu deste que foram as grandes tormentas e tempos adversos, que tivera, que o constrangeram a tornar para o Reino: “- Oh, Senhor, que mau anúncio esse para os bastardos, que até agora não houve filho de puta que não fosse ditoso!"

A curiosidade desse dito é a não surpresa de, na nota que o acompanha, não haver esclarecimento do sentido de "filho de puta". Quer dizer, a expressão com seu sentido até hoje usual está presente e corrente na língua desde antes do primeiro rastro escrito de "puta", no século XIII (Cunha, 1989:

3 Cf. Santiago-Almeida (2000 e 2009), Cunha (1986), Amaral (1976/[1920]), Penha (1970 e 1997), Silva Neto (1963), e Melo (1946), dentre tantos.

4 O estudo da ortografia, da pontuação e de possíveis aspectos fonéticos fica prejudicado, porque, conforme está esclarecido nos critérios para a edição (p.11), o texto, originalmente manuscrito, foi atualizado quanto à ortografia e pontuação.

5 Projeto de pesquisa "História e variedade do português paulista às margens do Anhembi", que investiga a formação e expansão do português paulista ao longo do rio Tietê até Mato Grosso a partir do séc. XVI. 
649), considerando que o registro escrito, com raríssimas exceções, sempre é posterior ao oral.

Dito 12 (p. 19), atribuído a el-rei Dom Manuel: "El-rei folgava muito muito com pernas de coelhos. Levando-lhes um coelho à mesa com uma perna menos, disse el-rei: - Que diligência de coelho, que vem num pé à mesa!"

A nota esclarece que "que vem num pé" é um aforismo relacionado com "ir num pé e vir no outro".

Dito 39 (p. 29), de el-rei Dom João III: "Tratando-se de dar uma certa dignidade a uma pessoa de que já el-rei soubera defeitos, de que havia dias que estava emendada, e não faltando a quem, no presente, lembrasse mais os defeitos que emenda, respondeu-lhe ele: - Não é razão que lhe faça nojo comigo o que já lhe não faz diante de Deus."

A nota desse dito elucida que "de que havia dias" e "faça nojo comigo" querem dizer, respectivamente, "de que havia já muito tempo" e "aborrecimento".

Dito 52 (p. 33), também atribuído a Dom João III: "Indo el-rei em uma procissão, estando em Almeirim, olhou para uma janela de um seu escrivão da câmara, a quem fazia muitas mercês para pessoas que se dizia que lho agradeciam com dádivas, e viu-lhe uma alcatifa branca com malhas pretas. E um fidaldo que ia junto a ele disse-lhe: - Senhor, por aquela alcatifa deu Fuão o preto no branco. Querendo dizer que o sinal de el-rei; e el-rei respondeu-lhe: - Mas nem preto nem branco."

A nota chama a atenção para "preto no branco", no sentido de "passar documento" ou "escrever um documento"; e também para "nem preto nem branco", fazendo referência a "não passar dinheiro algum" ou a "não fazer pagamento". A referência a "preto" e a "branco" para designar dinheiro, e daí ser a base da expressão "preto no branco" para significar "pagamento" e, por extensão, "documento", fica melhor esclarecido sabendo, pela mesma nota, que o "preto" e o "branco" eram as designações populares de moedas de real, respectivamente, de cobre e de prata.

Dito 372 (p. 145), de Tomé de Sousa: "Ouvindo Tomé de Sousa a umas damas que 'porque se não servia a rainha de vedor que fosse fidalgo de Dom?', disse-lhe ele: "- Muitos dias há que eu tivera Dom se quisera; mas, por não parecer bispo de anel, o deixei."

Esclarece a nota do editor que "muitos dias há" quer dizer "há muito tempo" ou "faz muito tempo". 
Dito 533 (p.193), de João de Sá, o Negro, falando a um fidalgo que era tido por mentiroso, quando este lhe perguntou sobre as novas [da corte]: “$\mathrm{Eu}$, Senhor, não conto novas senão quando são já tão maduras que mas dão a real; porque quem depressa as toma depressa as dá.”

Segundo a nota 88 (p. 46), João de Sá era um personagem da época de Dom João III, e teria sido uma espécie de bobo da corte, vivendo por lá como agregado e participando do dia-a-dia da nobreza portuguesa. A nota do dito 533 elucida que "dar a real" significa dizer o que se tem por "seguro", "sabido", verdadeiro".

Dito 759 (p. 281), do mesmo Dom João III: "Indo o conde [da Catanheira] para entrar, porque todas as manhãs tomava aquele tempo [de el-rei], tapoulhe o camareiro-mor a entrada."

O referido conde da Castanheira, explicita a nota, era muito próximo e amigo de D. João, o que causa inveja e ciúme nos demais que não tinham a mesma intimidade. A expressão "tomava aquele tempo", que pode ser reduzida a "tomar tempo", quer dizer que o tal conde "era recebido" pelo rei numa determinada hora todas as manhãs.

Dito 804 (p. 296), atribuído a uma fidalga dos tempos de Dom João III: "Uma fidalga viúva que vivia em Lisboa, estando um dia em um mosteiro, viu que uma moça muito formosa e recolhida, sentada diante dela, pôs uma mão muito alva na grade; e ela, dando-lhe nela rijo com uma cana, disse-lhe: - Tirai muito em má hora; e não ponhais ramo, pois não haveis de vender vinho."

O editor destaca na nota "em má hora", no sentido de censura, dizendo que é oposta à locução "em boa hora".

Dito 1103 (p. 394), de Diogo Navarro, músico do infante Dom Luís, relatando sobre um documento em que um escrivão dera sua fé.

A nota destaca "dar fé" acrescentando-lhe o correspondente "certificar", sentido que o editor considerar ser mais moderno no PE.

Dito 1436 (p. 483), também atribuído a Diogo Navarro, referindo-se a Tomé de Sousa: "Disse [Tomé de Sousa] que nunca fez das tripas coração e muitas vezes fez do caração tripas".

Por considerar a expressão "fez das tripas coração" fora de uso no cotidiano atual do PE, o editor supõe, em nota, que o sentido do dito "parece ser" que Tomé de Sousa "nunca quis armar em valente, antes pelo contrário". Quer dizer: nunca quis "bancar o valente, corajoso". 
252 Manoel Mourivaldo Santiago-Almeida; Manoella Neres Jubilato; Cátia Schreiner

\section{Ditos: lexias}

Nesta parte, destacaremos, na primeira coluna da tabela, apenas o verbete com referência, entre parênteses, ao dito, seguido da página em que se encontra. Na coluna paralela, aparecerão, na linha justaposta, o sentido moderno e ou comentário.

\begin{tabular}{|c|c|}
\hline Verbete em desuso no PE (dito: página) & $\begin{array}{l}\text { Correspondente moderno/ } \\
\text { comentário }\end{array}$ \\
\hline • Antemão (248: 104) & Antecipado. \\
\hline - Acanhar (30: 25) & Vexar, subordinar, envergonhar. \\
\hline - Acertar [de] (21: 22) e (293: 118) & Acontecer. \\
\hline - Arrecadar (31: 25) & Cobrar, arrecadar imposto. \\
\hline • Bordão (516) & $\begin{array}{l}\text { Palavra que se repete muitas vezes e } \\
\text { nome da corda da viola que serve } \\
\text { para o acompanhamento. }\end{array}$ \\
\hline - Cheirar (1050: 378) & Andar perfumado, perfumar-se. \\
\hline - Contentar-se (17: 21) & Ter grande satisfação. \\
\hline • Criação (949) & $\begin{array}{l}\text { Educação. Maneira ou sistema em } \\
\text { que alguém é criado. }\end{array}$ \\
\hline - Diferença (8: 18), (42: 30) e (315: 125) & Briga, conflito e discussão. \\
\hline - Embicar (1478: 489) & $\begin{array}{l}\text { Tropeçar. Este verbo conserva-se na } \\
\text { fala do brasileiro do interior no } \\
\text { sentido de lançar-sepor ou para } \\
\text { algum lugar. }\end{array}$ \\
\hline - Enojado (56: 34) & Contrariado, aborrecido. \\
\hline - Feder (1050: 378) & Cheirar mal. \\
\hline - Gracioso (90: 47) & Espirituoso. \\
\hline - Maldisposto (31: 25) e (238: 100) & Adoentado, doente. \\
\hline - Mexericar (113: 55) & Fazer intriga. \\
\hline
\end{tabular}


- Pelejar (315: 125)

Questionar. "Pelejar com os filhos."

No PB, mais propriamente no Rio

Grande do Sul, quer dizer: brigar, lutar, disputar, teimar.

- Pousar (75: 41)

Residir. No PB, costuma-se usar no sentido de passar a noite.

- Propósito (70: 40) Tema.

- Quitar (522: 190)

Dar por quite, perdoar. Quer dizer: dar por resolvido.

- Regateiras (66: 38)

Mulheres vendedoras, consideradas as mais afoitas em desobedecer às taxas impostas pela Coroa. Regateiro, pois, tem o sentido de ser afoito.

\begin{tabular}{ll}
\hline - $R e m a t a r ~(316: 125)$ & Concluir. \\
\hline - Remetido (60: 35) & Destinado. \\
\hline - Seguro (27: 24) & Firme. \\
\hline - Subscrição, subscrever (40: 29) & Garantia. \\
\hline Tachado (269: 110) & Assinatura, assinar. \\
\hline - Traquinada (450: 165) & $\begin{array}{l}\text { Censurado (de tacha, mancha, } \\
\text { defeito). }\end{array}$ \\
\hline - Zombar (288: 117) & Reboliço, desordem. \\
\hline
\end{tabular}

\section{Ditos: estilo}

O emprego de eu e nós é assunto. Hoje, no discurso, a escolha de eu ou nós para designar o locutor que se anuncia como sujeito é tida como uma questão de estilo. Quer dizer: dependendo do contexto discursivo e/ou da intencionalidade do sujeito, o eu e o nós se alternam. Em Ditos portugueses a questão é levantada no dito 7 (p. 17), atribuído a el-rei Dom João II. Eis o 
referido dito: "Todos o reis de Portugal até el-rei D. Manuel falavam por Nós, el-rei; somente el-rei D. João o Terceiro mudou isto em suas provisões e dizia Eu, el-rei. Falando um fidalgo a el-rei e, no discurso da prática, dizendo-lhe muitas vezes vós, disse el-rei: - Vós tendes mais de vós do que nós temos de nós."

A nota que acompanha este dito esclarece que o tratamento por $e$, em vez do tradicional nós, foi decretado em 1524 (Carneiro, 1937: 220). Esta era a fórmula do absolutismo régio. Os fidalgos que se dirigiam ao rei usavam o tratamento de Vossa Alteza, e não de vós. E é isso o que explica o comentário de Dom João II.

Observamos que no nosso cotidiano o uso de nós no lugar de en é constante no discurso político e também acadêmico. É a forma mais antiga, de antes do decreto de 1524. Percebe-se que o emprego deste pronome desfaz o tom real, supremo. Nós, no mínimo, pluraliza a unicidade que, quando o sujeito é $e \ell$, rege o mecanismo da enunciação. Por hipótese, talvez tenha sido este o motivo do decreto real (?).

Para ficar no campo dos pronomes, e ao mesmo tempo estender o assunto, vamos pular três séculos adiante dos originais dos ditos, do XVI para o XIX, mas pemanecer na sombra [e sobra] da nobreza.

Na carta de Dom Pedro II para sua "Cara Mana", editada abaixo, mudase a pessoa e número do pronome, da primeira do singular ou plural para a segunda do singular, $t u$. Trata-se também do mesmo discurso da prática que fez com que o fidalgo cometesse uma gafe ao se dirigir a el-rei, dizendo-lhe vós ao invés de Vossa Altera. Como sabemos todos, ainda hoje é comum no dircurso da prática, isto é, no cotidiano e em contexto informal, no PE, tué o pronome usado para alguém com quem se tem maior intimidade, como é o caso da interlocutora da carta de Dom Pedro II, no lugar de você, como é da nossa prática no $\mathrm{PB}$. 


\begin{tabular}{|l|}
\hline Edição diplomática justalinear \\
Rio 24 de Janeiro de 1863 \\
Cara Mana \\
Todos bons e estimo que succeda o mes- \\
mo por lá. Veras pelos jornaes quanto já se \\
tem feito e fará e estou certo de que \\
darás n'esta occasião uma prova mais do \\
teu brazileirismo, concorrendo como minha ir- \\
mãa, para os gastos da defeza do paiz. \\
O espirito mantem-se excelente eha males \\
que vem para o bem. \\
Não demoras a tua decisão a respeito do dote \\
que nas circunstancias actuais ainda mais op- \\
portuna se torna. \\
Lembranças ao Luis e a teus filhos, e \\
recebe este saudosissimo abraço de \\
Teu Mano do coração \\
Pedro
\end{tabular}


256 Manoel Mourivaldo Santiago-Almeida; Manoella Neres Jubilato; Cátia Schreiner

Fac-símile

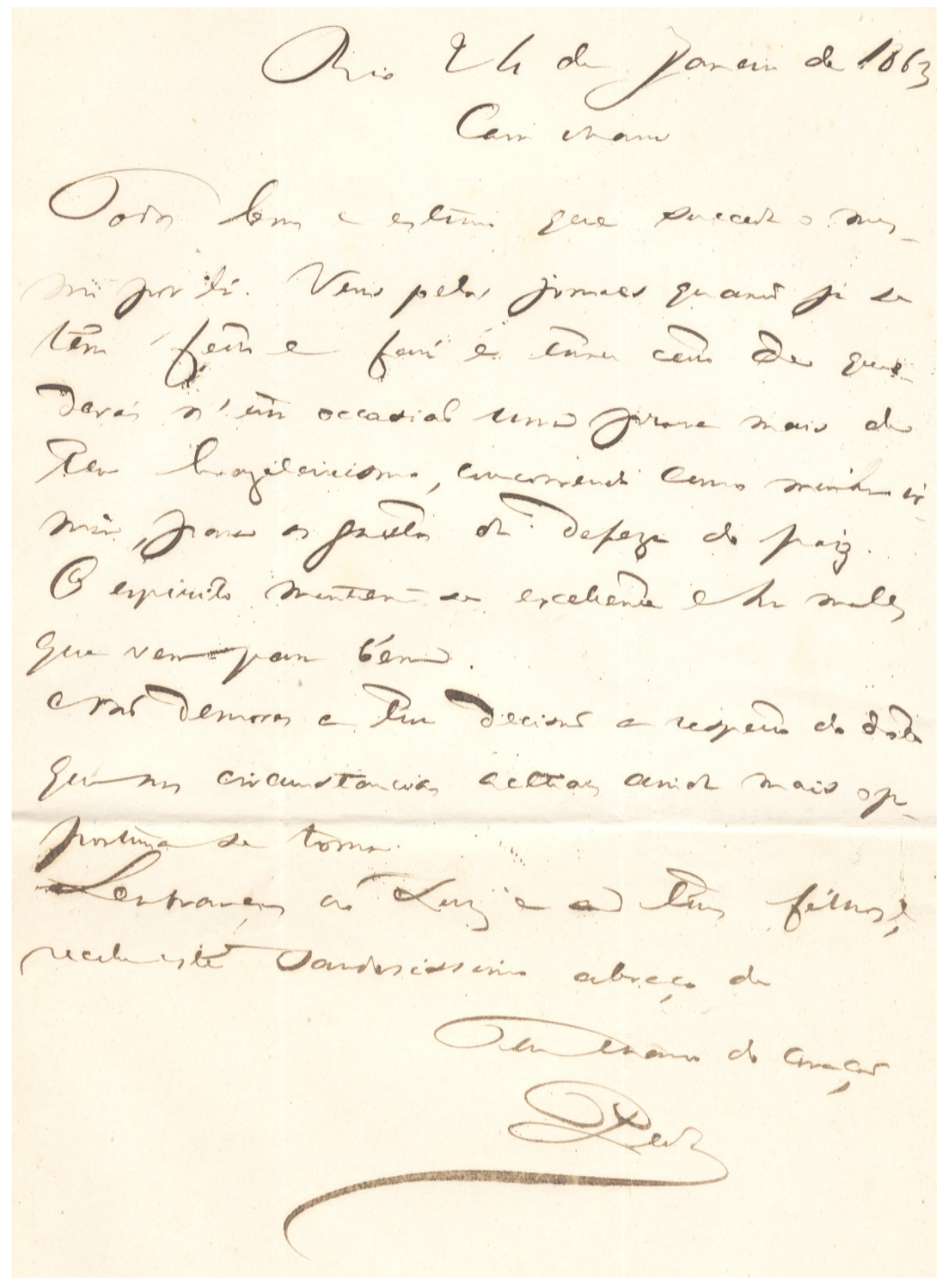

(Acervo dos autores)

\section{Considerações finais}

Para tratar de manutenção/inovação no PB, retomamos o ponto de vista de Cunha (1986: 200), que - partindo da tese sobre a unidade e arcaicidade 
do PB de Silva Neto (1963), e retomando Melo (1946), que faz referências a fenômenos que serviriam para provar o caráter conservador e anticlássico do nosso português da América- - procura mostrar que, "se o mito da unidade tem sido desmentido pela publicação de atlas linguísticos, o mito da arcaicidade parece mais resistente".

Levando em conta a situação linguística no início da colonização, conforme Cunha (1986: 202-204), o português, precariamente, começou a ser difundido no Brasil em 1532, com a instituição de capitanias hereditárias, e que desde a chegada dos portugueses no século XVI, avançando pelos séculos XVII e XVIII, é certo que vieram indivíduos das distintas regiões de Portugal, que naturalmente falavam a língua com a variedade do seu tempo, com matizes mais conservadores ou mais inovadores conforme as áreas de procedência.

De um modo geral é tido como certo que o norte português é conservador e se contrapõe a um sul inovador. A norma sulista, que representava um modelo seletivo, tinha maior poder de expansão, não precisando, portanto, de ser a do maior número de falantes nele radicados para se impor no Brasil.

Retomando esta afirmação, Cunha (1986: 202) diz ainda que "não apenas a língua culta, mas também a língua comum dos brasileiros, funda-se nessa neológica norma sulista dos séculos XVI e XVII", facilmente demonstrável assim na fonologia como na morfologia e na sintaxe, e que as divergências encontradas entre aquela e a atual norma brasileira são devidas a posteriores evoluções, tanto paralelas quanto distintas, em virtude, principalmente, do contato com outras línguas, como as dos índios e as trazidas pelos africanos.

No decorrer desses séculos as condições socioculturais no Brasil, principalmente em regiões interioranas, foram mais propícias à conservação ou manutenção do que a renovação ou inovação. Isto, no dizer de Cunha (1986: 202), é "de uma evidência que dispensa maior comprovação", porque tendo vivido mais de trezentos anos sem contato duradouro com outros povos, sem imprensa, sem núcleos culturais de importância, e com pouquíssimas escolas, o Brasil foi alcançando nesse vasto período algumas das etapas que consequentemente levam os povos aos "estados linguísticos paralisantes". ${ }^{6}$

6 Nessa discussão, Santiago-Almeida (2009: 125) lemba que é importante evidenciar que se está considerando apenas a variedade brasileira, produto da convivência do português europeu com as línguas indígenas e africanas do século XVI ao XVIII, sem levar em conta outras situações posteriores de contatos. 
No caso da área que estamos investigando desde 1996, do rio Tietê (SP) ao Cuiabá (MT), que passou a ter visibilidade a partir da mineração mais propriamente do século XVII ao XVIII, quando várias entradas foram organizadas, partindo a maioria delas de São Paulo -, as condições socioculturais não eram muito diferentes das descritas por Cunha (1986: 202).

Passada a época da mineração fértil, paralela à atividade dos tropeiros, os muitos vilarejos surgidos pelos caminhos bandeirantes, monçoeiros e tropeiros entraram em decadência e, de certa forma, isolados, implicando carência de contatos com outras culturas, permaneceram com seus costumes, manifestações culturais e religiosas e, consequentemente, com a variedade linguística próxima daquele tempo.

Esse estado, chamado por Cunha (1986: 203) de "imobilismo cultural", ainda muito sensível em regiões do interior brasileiro, contribuiu para encontrarmos ainda hoje, em suas variedades linguísticas, fenômenos, pricipalmente no nível fonético e semântico-lexical, que pertencem a estratos antigos da língua portuguesa - do arcaico ao século XVIII, incluido também o XIX -, quase todos comuns também no português popular falado no Brasil. ${ }^{7}$

Estamos fazendo referência aos fenômenos presentes em estágios anteriores do PE que, depois do estado de variação, foi substituído pela(s) forma(s) concorrente(s). Trata-se de realizações que deixaram de ser usuais, frequentes, recorrentes, nas normas ou variedades atuais do PE, exemplificadas, neste texto, pelos casos do nível semântico-lexical extraídos do livro Ditos portugueses dignos de memória, que serve para testemunhar as sobras e sombras nobres e plebeias do século xvi que nos foram deixadas de legado.

Embora saibamos que não é de hoje que estudos sobre a evolução histórica do português vêm apontando traços antigos no português corrente no Brasil, dando-lhe, assim, matiz de variedade conservadora em oposição à inovadora europeia, com este texto temos a intenção continuar a discussão sobre esse grau de inclinação ao caráter conservador do PB.

Por fim, lembramos que há de se reconhecer, ainda, que em pesquisa linguística - principalmente quando se discute a variedade de uma dada língua, com o risco de lhe imprimir um único selo ou the caracterizar por apenas uma de suas multifaces - o que se pode destacar, dentro do redemoinho da

Para tanto, cf. Castilho (2010), Brandão (2007), Santiago-Almeida; Cox (2005); Aguilera (1994), Tarallo (1994), e outros. 
variação infinita de uma língua, são tendências ao maior ou menor grau de inclinação para uma ou outra de suas faces. Aí, por ser a língua produto da ação histórico-sócio-cultural de seus falantes, podemos rumar por caminhos distintos, quão distinta seja essa ação histórica, social e cultural.

\section{Bibliografia}

AGUILERA, Vanderci de Andrade. 1994. Atlas linguístico do Paraná. Curitiba: Imprensa Oficial do Paraná.

AMARAL, Amadeu. 1976/[1920]. O dialeto caipira. $3^{a}$ edição. São Paulo: HUCITEC.

BRANDÃO, Silvia Figueiredo. 2007. Nas trilhas do -R retroflexo. Signum: Estudos da Linguagem 10/2. 265-283

CARNEIRO, Pero de Alcaçova. 1937. Relações de Pêro de Alcáçova. Lisboa: Imprensa Nacional. CASTILHO, Ataliba T. de. 2010. Nova gramática do português brasileiro. São Paulo: Contexto.

CUNHA, Celso Ferreira da. 1986. Conservação e inovação no português do Brasil. O Eixo e a Roda 5. 199-230.

CUNHA, Antônio Geraldo da. 1989. Dicionário etimológico nova fronteira da língua portuguesa. $2^{\mathrm{a}}$ edição. Rio de Janeiro: Nova Fronteira.

MELO, Gladstone Chaves de. 1946. A lingua do Brasil. Rio de Janeiro: Agir.

PENHA, João Alves Pereira. 1970. A arcaicidade da lingua popular brasileira. Franca: Tese (Doutorado) - FFLCH.

PENHA, João Alves Pereira. 1997. Português rural de Minas numa visão tridimensional: na fala, nos textos regionais, nos escritores antigos. Franca: UNESP.

SANTIAGO-ALMEIDA, Manoel Mourivaldo. 1998. Resenha: Ditos portugueses dignos de memória. Filologia e Linguística Portuguesa 2. 233-239.

2000. Aspectos fonológicos do português falado na Baixada Cuiabana: traços de língua antiga preservados no Brasil. São Paulo: Tese (Doutorado) - Universidade de São Paulo.

; COX, Maria Inês Pagliarini (orgs.). 2005. Vozes Cuiabanas: estudos linguísticos em Mato Grosso. Cuiabá: Catedral.

sidade de São Paulo.

2009. Vogais do falar ribeirinho cuiabano. São Paulo: Tese (Livre-Docência) - Univer-

SILVA NETO, Serafim da. 1963. Introdução ao estudo da lingua portuguesa no Brasil. $2^{a}$ edição. Rio de Janeiro: Instituto Nacional do Livro.

TARALLO, Fernando. 1994. Tempos linguísticos - Itinerário histórico da lingua portuguesa. São Paulo: Ática. 